\title{
Proposta didàctica. Encapsulació de pols de peles de mandarina en boles d'alginat de calci. Aplicació com a sorbent del blau de metilè.
}

\author{
Dra. Àngels Olivella Costa \\ INS Baix Empordà (Palafrugell) \\ molivel6@xtec.cat \\ Dra. Núria Fiol Santaló \\ Departament d’Enginyeria Química, Agrària i Tecnologia, UdG. \\ nuria.fiol@udg.edu \\ Sergi Ortiz Aparicio \\ INS Baix Empordà (Palafrugell)
}

Resum • Les aigües residuals de la indústria tèxtil han estat estudiades al llarg del temps degut als problemes ambientals que genera el seu abocament a les aigües naturals. El blau de metilè és un colorant catiònic àmpliament utilitzat en la indústria de paper i del teixit. Tot i que no es considera un colorant molt tòxic, pot tenir diversos efectes nocius sobre els organismes vius i un cop inhalat pot causar diversos trastorns per a la salut humana. En aquesta experiència didàctica s'explica com encapsular pols d'un residu de fruita en alginat de calci i posteriorment s'ha estudiat la seva capacitat d'eliminació del blau de metilè en fase aquosa en funció de diferents temps de contacte. La següent experiència didàctica consta de cinc sessions amb una durada total de 16 hores que s'ha extret del treball de recerca dut a terme per un alumne de $1 \mathrm{r}$ de Batxillerat, Sergi Ortiz Aparicio.

Paraules clau - Recta de calibratge, blau de metilè, sorció, boles d'alginat de calci, contaminació de l'aigua, espectrofotòmetre visible

\section{Didactic proposal. Encapsulation of tangerine peel dust in calcium alginate balls. Implementation as a methylene blue sorbet.}

\begin{abstract}
Waste water in the textile industry has been studied over time due to the environmental problems generated by its spillage in natural waters. Methylene blue is a catiònic dye widely used in paper colouring, cotton and wool dyeing, and coating for paper stock. Although it is not considered as a very tòxic dye, it can have various harmful effects on líving organisms and once inhaled it may cause several disorders to human health. In this study, removal capacities of aqueous methylene blue (MB) by different formats of tangerine peels have been investigated: hidrated, dehydrated and dust tangerine peels encapsulated in alginated beads have been investigated in function of diferent contact times. The following teaching experience consists of five sessions with a total duration of 16 hours. It has been inspired from a research work carried out by student in the $1^{\text {st }}$ year of Batxillerat named Sergi Ortiz Aparicio.
\end{abstract}

Keywords • calibration curve, methylene blue, sorption, alginated calcium beads, Water contamination, spectrophotometer visible 
La proposta didàctica que es recull en aquest article està pensada per que la portin a terme un grup d'alumnes de $1 \mathrm{r}$ o de $2 \mathrm{n}$ de batxillerat (uns quatre màxim). S'espera que l'alumnat aprengui diferents conceptes experimentant ("learning by doing"). Es realitzarà només una sessió teòrica inicial per tal de donar una visió global del tema. També s'espera que els alumnes facin un bloc didàctic de cada sessió $i$ que de forma il-lustrada vagin reflectint tot el procés de l'activitat.

\section{SESSIÓ 1. INTRODUCCIÓ (1 H)}

Activitat programada. Explicar en termes generals en què consisteix el treball.

Tasques docent. Fer un breu resum del treball. Cal fer èmfasi que els alumnes entenguin els termes: sorció (explicar les diferències entre Adsorció "sorció superficial" i Absorció "sorció que arriba a l'interior del material"), sorbent, blau de metilè (usos i propietats, Figura 1) contaminants, polimerització. Cada alumne tindrà aquesta proposta i el professor a partir d'un gràfic amb conceptes clau (colorants, contaminants, sorbents, encapsulació) farà l'explicació. El context del treball seria el següent:

Els colorants s'utilitzen en moltes indústries: alimentària, paper, tèxtil, plàstic etc. L'abocament de residus de colorants en aigües naturals no només afecta l'estètica, sinó que també interfereix en la transmissió de la llum solar $\mathrm{i}$, per tant, redueix l'activitat fotosintètica (Mall et al. 2006). El blau de metilè és un tint catiònic àmpliament utilitzat per pintar paper, tenyir de cotó i llana i revestir paper. Tot i que no es considera un colorant molt tòxic, pot tenir diversos efectes nocius sobre els organismes vius (Cengiz \& Cevas 2008) i, un cop inhalat, pot causar diversos trastorns a la salut humana (nàusees, vòmits, confusió mental i dificultats per respirar). L'abocament d'aigües residuals de colors de les indústries que utilitzen colorants pot suposar un perill eco-tòxic $\mathrm{i}$ introduir el potencial perill de bioacumulació, que pot afectar l'home a través de la cadena alimentària.

Per a l'eliminació de contaminants orgànics de les aigües residuals, s'ha utilitzat el carbó activat

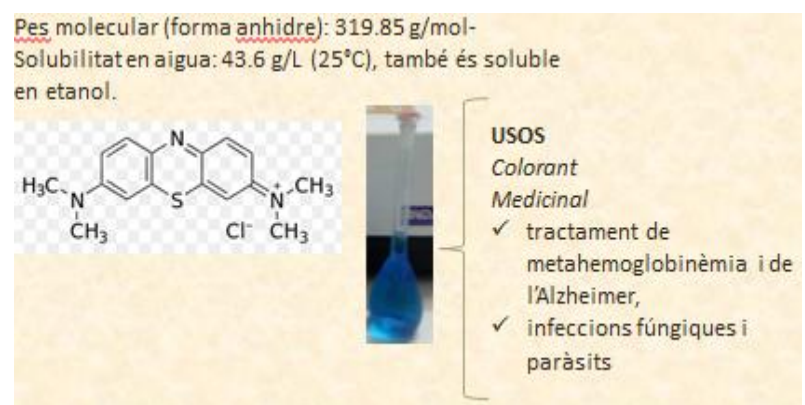

Figura 1: Característiques químiques i usos del blau de metilè.

com a sorbent; no obstant això, el cost del carbó activat és relativament elevat i la regeneració és difícil, la qual cosa limita el seu ús en el tractament de residus de colorants (Waranusantigui et al. 2003). Com a resultat, molts investigadors han investigat substituts biodegradables de baix cost fets a partir de recursos naturals per eliminar contaminants orgànics, com els colorants, de les aigües residuals (Gupta \& Suhas 2009; Sharma et al. 2011). S'han provat diferents tipus d'aquests biosorbents de baix cost tant en proves en discontinu com en columnes (Sharma et al. 2011; Zhang et al. 2011).

En aquest treball s'ha escollit com a sorbent la pela de mandarina perquè és un residu poc valoritzat. Tanmateix, no es coneixen molts estudis de sorció on s'utilitzin peles de fruites.

En aquest estudi també hem emprat l'alginat de calci el qual s'extreu de diferents espècies d'algues marines (Laminaria, Macrocystis, Ascophyllum) per encapsular la pols de pela de mandarina. Aquest polímer, tot i no presentar una resistència mecànica elevada, presenta avantatges respecte altres polímers ja que, quan es produeix la polimerització, el material està perfectament encapsulat en el seu interior i no es produeixen pèrdues de material quan les boles formades es posen en contacte amb una solució (Fiol, 2005).

El procés de polimerització es forma a partir del desplaçament del grup de l'hidrogen del grup carboxílic de dues cadenes, de manera que el calci actua de pont entre dues cadenes. La repetició d'aquesta estructura forma el gel d'alginat càlcic (https://unabiologaenlacocina.wordpress.com/2015/ 03/11/esferificacion-la-tecnica-que-inicio-lagastronomia-molecular/). 
Tot i que l'alginat de calci s'ha utilitzat per encapsular materials biològics (enzims, fongs) $i$ també residus vegetals no es coneix cap referència sobre la utilització per encapsular pols de pela de mandarina. Per tant, la combinació d'un nou sorbent a partir de la combinació del residu de fruita, la pela de mandarina, i el polímer constitueix una novetat. L'alginat de calci és un polímer molt emprat bàsicament perquè és senzill de trobar, de sintetitzar i és econòmic. Per això, sembla que aquest polímer pot ser una bona matriu per encapsular pols de pela de mandarina sense que suposi un augment significatiu del cost de l'adsorbent.

Tasques estudiants. Entendre els conceptes claus i quins són els objectius de l'experiència:

1. Encapsular pols de pela de mandarina en boles d'alginat de calci

2. Aplicació de les boles com a sorbent del blau de metilè.

Al final de la sessió el docent farà unes preguntes per saber si els alumnes han assolit els conceptes claus. A cada sessió s'aniran repassant els conceptes claus del treball per tal de que els alumnes ho assimilin.

\section{SESSIÓ 2. PREPARACIÓ DE L'ENCAPSULACIÓ DE LA POLS DE PELA DE MANDARINA EN BOLES D'ALGINAT DE CALCI (4 h)}

Activitat programada. Encapsular pols de pela de mandarina en boles d'alginat de calci. Haurem de seguir els següents passos:

1. Triturar les peles de mandarina deshidratades en el molinet de cafè, fins que s'obtingui un polsim d'uns $5 \mathrm{~mm}$. (Figura 2)

2. Preparem una dissolució del $1 \%$ d'alginat de sodi en aigua $(1 \mathrm{~g}$ d'alginat de sodi en $100 \mathrm{~mL}$ d'aigua destil-lada) i se li afegeix la pols poc a poc mentre s'està agitant i escalfant (Figura 3 ) Aquesta dissolució es va escalfant fins a $80^{\circ} \mathrm{C}$ en un vas de precipitats tapat per tal d'evitar l'evaporació de l'aigua i en agitació constant.

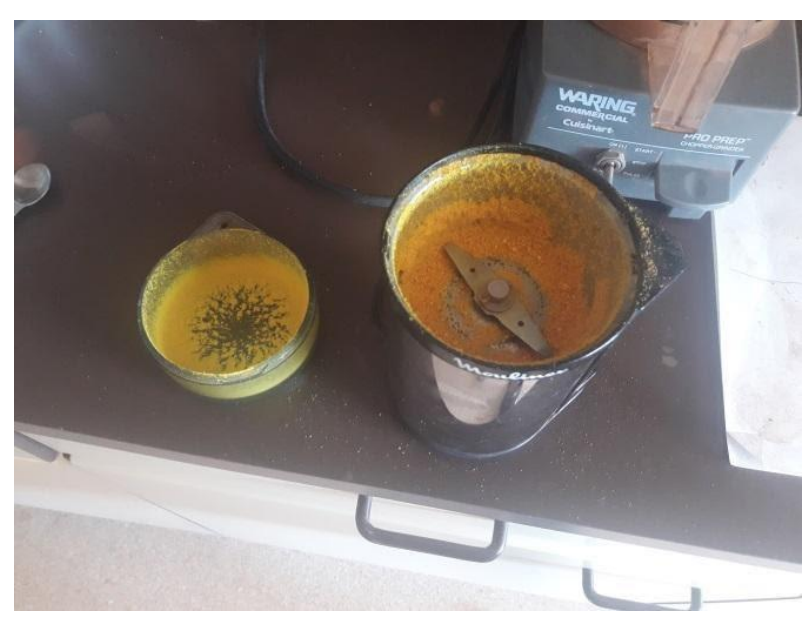

Figura 2: Procediment de preparació de les boles d'alginat de calci.

3. Deixem refredar la dissolució d'alginat de sodi en aigua.

4. Preparem $200 \mathrm{~mL}$ d'una dissolució de $\mathrm{CaCl}_{2}$ de concentració $0,1 \mathrm{M}$, que s'utilitza com a font de calci per formar les boles d'alginat de calci (Figura 4).

5. La dissolució de l'esquerra es fa circular per un tub mitjançant la bomba peristàltica (Figura 5).

6. A la sortida del segon tub es col-loca una micropipeta de diàmetre $1,5 \mathrm{~mm}$. En caure les gotes de la dissolució del $1 \%$ d'alginat de sodi en aigua ( $1 \mathrm{~g}$ d'alginat de sodi en $100 \mathrm{~mL}$ d'aigua destil-lada) dins de la dissolució de $\mathrm{CaCl}_{2}$ de concentració $0.1 \mathrm{M}$ es produeix la formació de les boles a través del procés de polimerització descrit a la introducció.

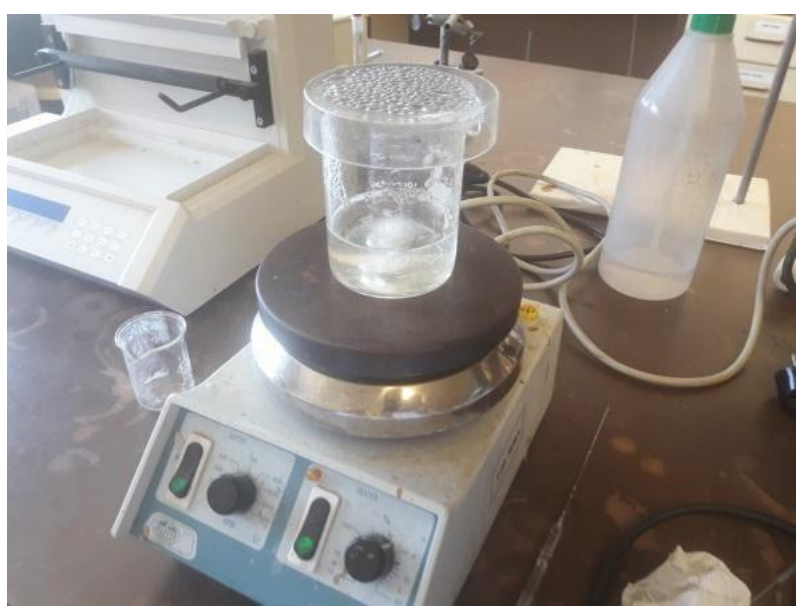

Figura 3: Solució 1\% d'alginat de sodi sense pols de pela de mandarina 


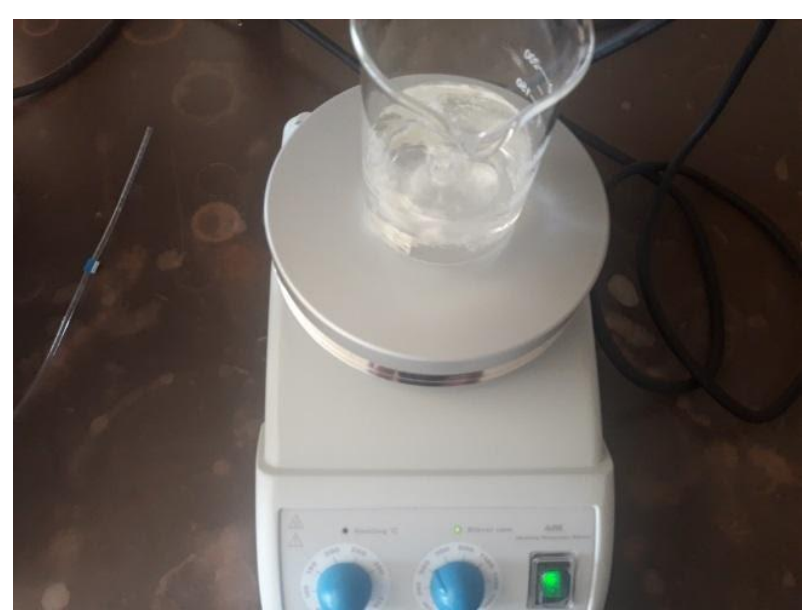

Figura 4: Solució de $200 \mathrm{~mL}$ de $\mathrm{CaCl}_{2}$

Seguidament es procedeix a la mesura amb un peu de rei de les boles d'alginat de calci amb la pols de pela de mandarina encapsulada (Figura 6).

7. El blanc de les boles es el mateix procediment però en el pas 2 no hi afegim la pols de pela de mandarina.

8. Les boles es guarden en un recipient tancat en aigua destillada a la nevera fins a la propera utilització.

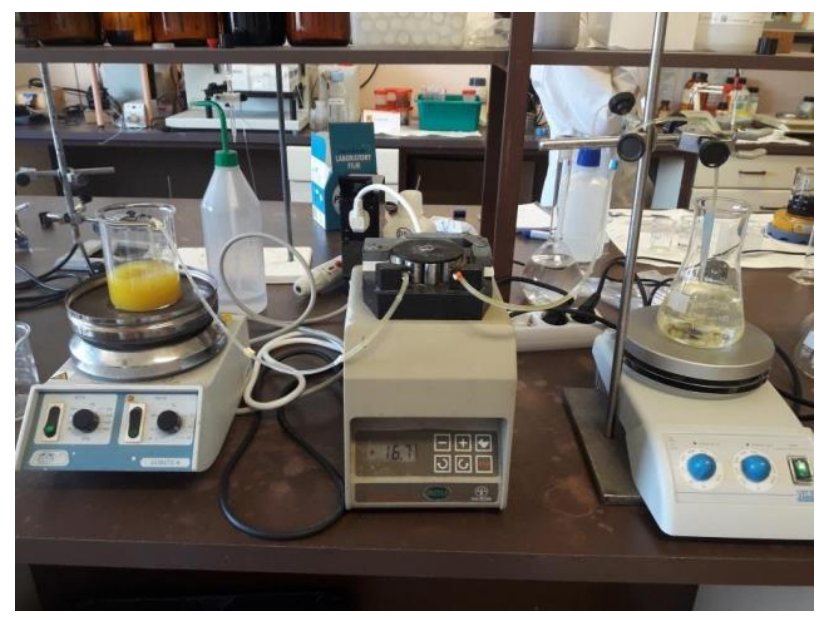

Figura 5: Procediment de preparació de les boles d'alginat de calci

\section{Material}

Reactius:

- Alginat de sodi: FlukaBiochemika, Steinheim (Suïsa)

- $\mathrm{CaCl}_{2}$ : Panreac, Monplet \& Esteban, Barcelona

- $10 \mathrm{~g}$ de boles d'alginat de calci encapsulades

- $10 \mathrm{~g}$ de peles de boles d'alginat de calci sense encapsular (blanc)

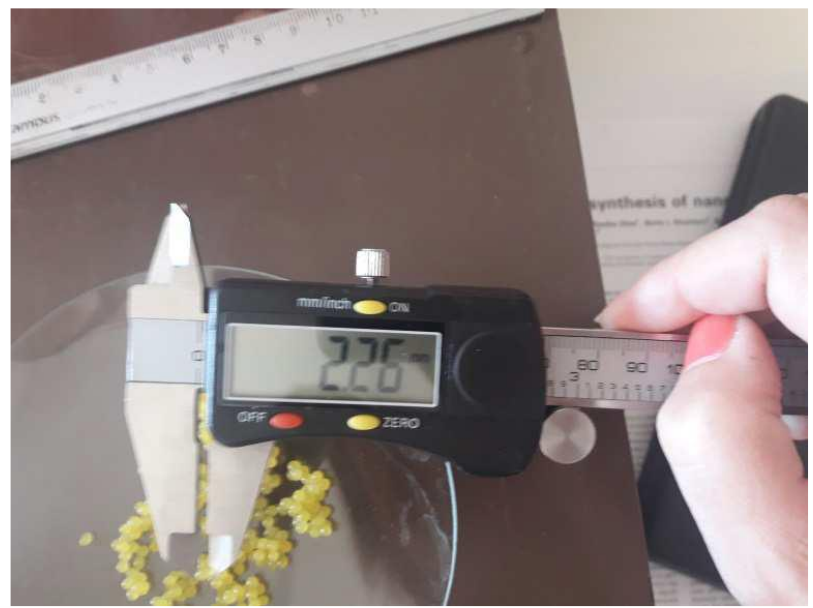

Figura 6: Mesura amb un peu de rei de les boles d'alginat de calci amb la pols de pela de mandarina dins.

Instruments i eines:

- Agitador rotatori de tubs Cenco Instruments

- Vas de precipitats

- Balança

- Molinet de cafè

- Bomba peristàtica

- Micropipeta

Tasques docent. Donar les explicacions sobre els passos a seguir $i$ els fonaments bàsics de la polimerització. Explicar els conceptes del blanc i la importància de la preparació. Acompanyar l'alumne en tot el procés de laboratori.

Tasques estudiant. Apuntar les idees més importants i formular preguntes. Fer fotos/vídeos del procediment i incloure-les al bloc.

\section{SESSIÓ 3. PROCÉS DE SORCIÓ (6 h)}

Activitat programada. Utilitzar les boles de la sessió 2 com a sorbent del blau de metilè (BM) o com a eliminació del blau de metilè en solució. Els passos a seguir seran els següents:

1. Es pesen $10 \mathrm{~g}$ de pols de mandarina encapsulada en boles d'alginat de calci. (sorbent) i $10 \mathrm{~g}$ de boles no encapsulades (blanc).

2. Es preparen dues solucions de $100 \mathrm{~mL}$ de solució de BM $0.6 \mathrm{~g} / \mathrm{L}$ (una és el blanc i l'altre s'hi introduirà el sorbent)

3. Es posen els grams de sorbent dins en cadascuna de les solucions de BM i s'agita a 500 rpm (Figura 7). 
4. Es prenen mostres de la solució cada $5 \mathrm{~min}$, $15 \mathrm{~min}, 30 \mathrm{~min}, 90 \mathrm{~min}, 150 \mathrm{~min}, 210 \mathrm{~min}, 270 \mathrm{~min} \mathrm{i}$ 330 min i es mesura l'absorbància a $665 \mathrm{~nm}$ (absorbància màxima del blau de metilè). Es realitzen dues mesures i es fa la mitjana de les dues.

Material

- Espectrofotòmetre $\mathrm{V}-10$ plus ONDA

- Dos vasos de precipitats de $200 \mathrm{~mL}$

- Blau de metilè Scharlau $500 \mathrm{~mL}$ Ref. AZ02060500

- Aigua destil-lada

- Matrassos de $100 \mathrm{~mL}$

- Lleixiu pel rentat

- Dos agitadors (Agimatic-N, Nahita 690-2)

- Dos mosques magnètiques

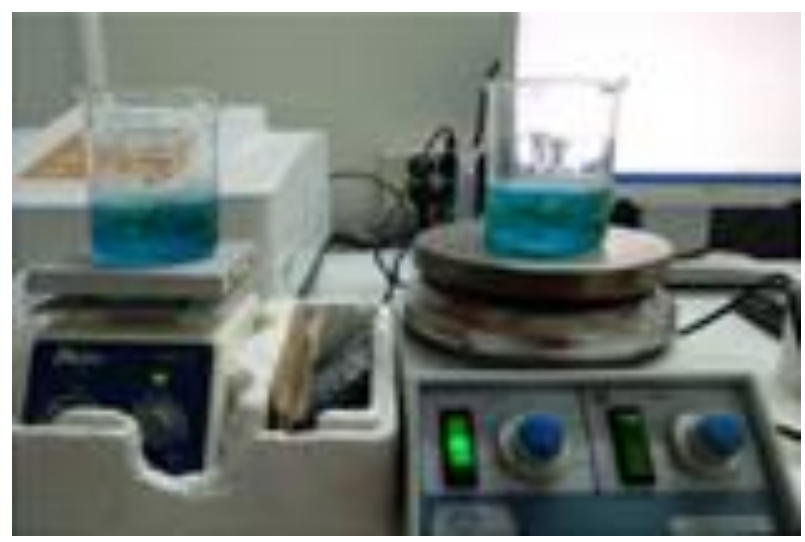

Figura 7: Procés de sorció entre els sorbents i el blau de metilè

Tasques docent. Explicar els conceptes de sorció i de blanc de la mostra en aquest experiment. Plantejar als alumnes com es prepara $100 \mathrm{~mL}$ una solució de BM $0.6 \mathrm{~g} / \mathrm{L}$. Acompanyar els alumnes en el procés de laboratori.

Tasques estudiants: formular preguntes, fer fotos/vídeos del procediment i reflectir-ho al bloc. Per tal de saber si els alumnes han entès bé el procediment se'ls formularà una sèrie de preguntes que caldrà que raonin. Aquestes a tall d'exemple poden ser:

1. Com podem saber la banda d'absorció màxima del BM?

2. Com podem saber si són les boles o la pols de mandarina que absorbeix el BM?

3. La sorció es produeix immediatament o de forma regular al llarg del temps?
4. Creus que una aigua industrial (per exemple indústria tèxtil que fan servir el BM per tenyir texans) l'eliminació del BM per les boles encapsulades amb pols de mandarina (en les mateixes condicions que hem fet servir nosaltres) seria la mateixa? Quins altres factors creus que influeixen en la sorció?

\section{SESSIÓ 4. ANÀLISI I DETERMINACIÓ DEL BLAU DE METILÈ (3 h)}

Activitat programada: en el pas anterior hem tret diferents porcions de BM en diferents temps de contacte. En aquesta sessió es determinarà la concentració de BM en solució amb l'espectrofotòmetre visible ONDA V-10 PLUS (Figura 9). Els passos a seguir són els següents:

1. Es preparen quatre solucions de $0.15 \mathrm{~g} / \mathrm{L}, 0.3$ $\mathrm{g} / \mathrm{L}, 0.45 \mathrm{~g} / \mathrm{L}$ i $0.6 \mathrm{~g} / \mathrm{L}$ a partir d'una solució mare de BM de $30 \mathrm{~g} / \mathrm{L}$ (Taula 1).

2. Preparar un blanc amb aigua destil.lada i col-locar-lo a la posició 1 de les cubetes de l'espectrofotòmetre visible ONDA V-10 PLUS (Figura 8).

3. Fer el zero i operation start, mesurant l'absorbància del blanc (ha de donar 0.0000).

4. Mesurar l'absorbància de cada solució a $665 \mathrm{~nm}$.

5. Un cop es tenen totes les absorbàncies per cada concentració es prepara un gràfic amb el programa Excel on a l'eix y les absorbàncies i a l'eix $x$ les concentracions (Figura 9).

6. Un cop tenim la recta de calibratge

$$
A=C X+D
$$

Sent $A=$ absorbàncies $i \mathrm{C}=$ concentracions

Per obtenir la concentració a partir de l'absorbància aillem la variable $X$

$$
\begin{gathered}
(A-D) / C=X \\
\mathrm{~A}=1.6093^{*} \mathrm{C}-0.0224 \\
\mathrm{C}=(\mathrm{A}+0.0224) / 1.6093
\end{gathered}
$$




\begin{tabular}{|c|c|c|}
\hline $\begin{array}{l}\text { Solucions } \\
\text { (g/L) }\end{array}$ & $\begin{array}{c}\mathrm{mL} \text { de } 30 \\
\mathrm{~g} / \mathrm{L}\end{array}$ & $\begin{array}{c}\text { Procediment } \\
\text { Matràs de } \\
100 \mathrm{~mL}\end{array}$ \\
\hline 0.15 & 0.5 & \multirow{4}{*}{$\begin{array}{c}\text { Pipetegem } \\
0.5,1,1.5 \text { i } 2 \\
\mathrm{~mL} \\
\text { Enrasem a } \\
100 \mathrm{~mL} \text { amb } \\
\text { aigua } \\
\text { destil.lada }\end{array}$} \\
\hline 0.3 & 1 & \\
\hline 0.45 & 1.5 & \\
\hline 0.6 & 2 & \\
\hline
\end{tabular}

Taula 1: Procediment per a la preparació de la recta de calibratge.

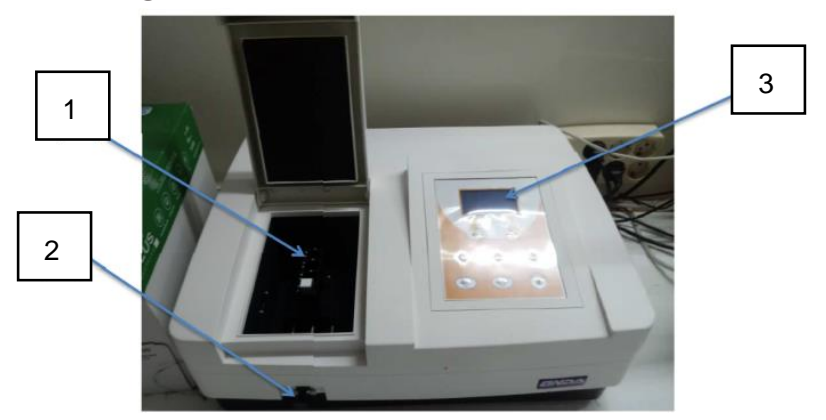

Figura 8: Espectrofotòmetre visible ONDA V-10 plus 1. Posició cubetes; 2. Maneta de canvi; 3. Lectura de les mesures.

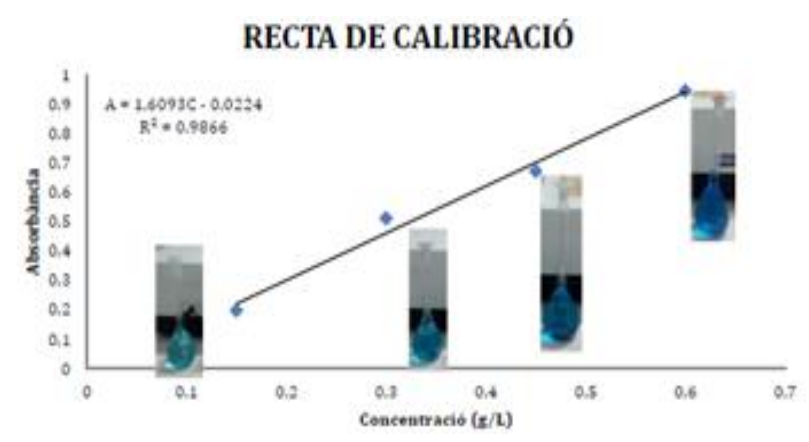

Figura 9: Recta de calibratge amb quatre solucions patró.

Val a dir que amb l'espectrofotòmetre es pot calcular directament la recta de calibratge. Hem pensat que per entendre el concepte de recta és millor que les alumnes representin els punts $\mathrm{i}$ obtinguin la recta de regressió amb el software excel ja que obliga a fer-ho pas a pas.

Material

- Espectrofotòmetre V-10 plus ONDA

- Matrassos de $100 \mathrm{~mL}$ amb tap

- Pipetes de $2 \mathrm{~mL}$ i pipetejador

- Aigua destil-lada i lleixiu
- Escovilló

- Blau de metilè Sharlau $500 \mathrm{~mL}$ Ref. AZ02060500

Tasques docent. Explicar els conceptes bàsics de l'espectrofotometria (absorbància), com funciona l'aparell pel seu anàlisi $i$ el sentit de la recta de calibratge. El docent ha de supervisar els càlculs per la preparació de la recta de calibratge.

Tasques estudiants. Formular preguntes, fer fotos del procediment i portar a terme les tasques de laboratori.

\section{SESSIÓ 5. INTERPRETACIÓ DELS RESULTATS OBTINGUTS (2 h)}

Activitat programada. Elaborar el gràfic amb el \% eliminació del BM respecte el temps. Interpretar els resultats. Un exemple del gràfic que es pot obtenir es presenta a la Figura 10.

\section{Material}

Excel o un programa similar que permeti fer gràfics

Tasques docent. Explicar com s'elabora el gràfic i explicar a l'alumne que el que hem esbrinat és un \%eliminació del BM en solució NO un \%de sorció del BM en les boles. Proporcionar articles on s'hagin fet experiments similars.

Un exemple d'explicació de la Figura 11 utilitzant la terminologia correcta seria:

A la figura 11 es pot veure el \% d'eliminació del blau de metilè per les boles d'alginat de calci i el de les peles de mandarina encapsulades en boles d'alginat de calci. Podem veure que ja als $15 \mathrm{~min}$ l'eliminació superava el $80 \%$. Per tant la màxima eliminació del BM es produeix als primers minuts. Al final del procés d'eliminació del BM de les peles de mandarina encapsulades en boles d'alginat de calci és del $93 \%$ i del blanc (boles d'alginat de calci sense encapsular) és del $86 \%$. Aquests resultats evidencien que la sorció es produeix majoritàriament per les boles d'alginat de calci. Un $7 \%$ de la sorció es deguda a la pols encapsulada. 


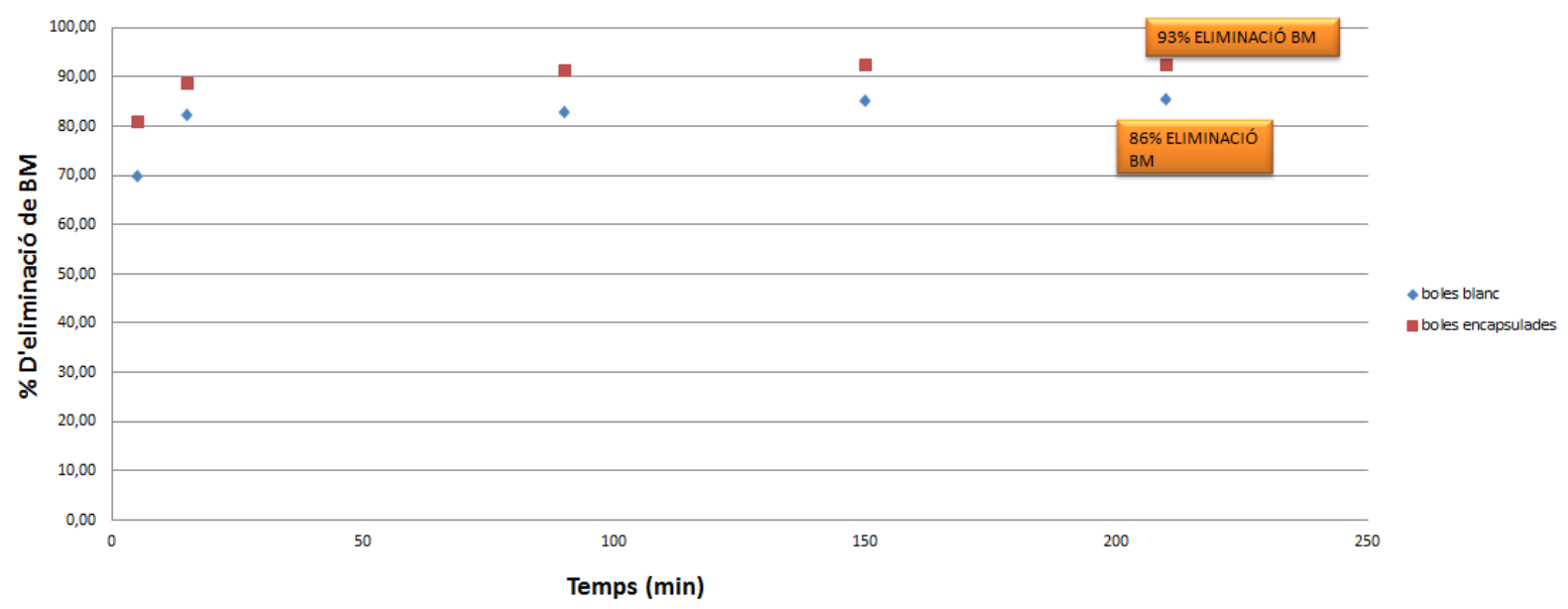

Figura 10:Comparació del \% d'eliminació del blau de metilè per les boles d'alginat de calci. Concentració inicial BM = $0.6 \mathrm{~g} / \mathrm{L}$.

Si comparem aquesta capacitat d'eliminació del blau de metilè amb estudis anteriors realitzats per altres autors, podem dir que la pols de mandarina encapsulada té la mateixa eficiència que el carbó actiu (Olivella et al., 2012) on autors han obtinguts percentatges al voltant del $90 \%$. També s'han obtingut percentatges d'eliminació elevats quan s'ha investigat l'eliminació del blau de metilè per microalgues (90\%) (Angulo et al., 2012) i per fulles (98,69\%) (Sánchez-Orozco et al.,2018).

Moreno et al. van estudiar també l'eliminació del BM en pellofes d'arròs i va obtenir un $99 \%$ d'eliminació en $163 \mathrm{~min}$ i $10 \mathrm{mg} / \mathrm{L}$ de concentració inicial de BM. Així doncs, malgrat l'eliminació és també molt bona, no és tan ràpida com la que s'ha obtingut en aquest estudi.

Albis et al. 2017 van obtenir percentatges d'eliminació del BM (concentració inicial 0.1-0.8 g/L) del $99 \%$ i una adsorció de $80 \mathrm{mgBM} /$ asorbent per closca de iuca modificada amb àcid fosfòric a altes temperatures $\left(127^{\circ} \mathrm{C}\right)$.

Tasques estudiants: Elaborar un text explicatiu del gràfic utilitzant la terminologia correcta. Molt important recalcar que hem calculat un \% d'eliminació del BM en solució i NO un \% de sorció del BM en les boles. Suposem evidentment que el que s'ha eliminat, s'ha adsorbit en les boles però és un càlcul indirecte. Algunes frases a nivell orientatiu que podem utilitzar per explicar el gràfic $i$ que els alumnes haurien de completar són:
- Als primers minuts el percentatge d'eliminació del BM per les boles d'alginat és...

- Als primers minuts el percentatge d'eliminació del BM per les boles encapsulades amb pols és....

- La diferències dels dos percentatge ens dona la sorció ........ El càlcul de sorció de la pols de pela de mandarina és un càlcul directe $o$ indirecte?

- Si unim tots els punts de la corba dels percentatges d'eliminació des del punt $(0,0)$ descriu com és el perfil de la corba (lineal, exponencial, logarítmica...)

- Quina diferència hi ha entre el percentatge d'eliminació i el percentatge de sorció? Quins dels dos termes és més correcte en el nostre cas? Per què?

\section{BIBLIOGRAFIA}

Albis, AA., López, JA., Romero, MC. (2017). Remolición de azul de metileno de soluciones acuosas utilizando cáscara de yuca (Manihot esculenta) modificada con ácido fosfórico. Prospectiva, 25, 60-73.

Angulo, E., Castellar, G., Avendaño, E. \& Barrios, M. (2012). Remoción de azul de metileno por la microalga chlorella sp. Viva Prospectiva, 10(1), 53-60.

Fiol, N. (2005). Aprofitament de residus vegetals per a la concentració i separació d'ions metàl-lics de solucions aquoses. (Tesis doctoral). Universitat de Girona, Girona. 
Gupta, VK. \& Suhas. (2009). Application of low-cost adsorbents for dye removal - A review. Journal of enviromental management, 90 (8), 2313-2342. https://doi.org/10.1016/j.jenvman.2008.11.017

Mall, I.D., Srivastava, V. \& Agarwal, N.P. (2006). Removal of Orange-G and Methyl Violet dyes by adsorption onto bagasse fly ash-kinetic study and equilibrium isotherm analyses. Dyes and Pigments, 69, 210-223.

Moreno, A., Figueroa, D.\& Hormaza, A. (2012). Adsorción de azul de metileno sobre cascarilla de Arroz. Produccion+Limpia,7(1), 9 - 18.

Olivella, A., Fiol, N., De la Torre, F., Poch, J.\& Villaescusa, I. (2012). A mechanistic approach to methylene blue sorption on two vegetable wastes: corkbark and grape stalks. Bioresources 7(3), 3340 - 3354.
Sánchez-Orozco, R., Martínez-Juan, M., García-Sánchez, JJ.\& Ureña-Nuñez, F. (2018).Removal of methylene blue from aqueous solution using Typhastems and eaves. Bioresources, 13, 1696-1710.

Sharma, P., Kaur, H., Sharma, M. \& Sahore V. (2011). A review on applicability of naturally available adsorbents for the removal of hazardous dyes from aqueous waste. Environ. Monit. Assess. 183, 151-195.

Waranusantigui, P., Pokethitiyook, P., Kruatrachue, M.\& Upatham, E.S. (2003).Kinetics of basic dye (methylene blue) biosorption by giant duck weed (Spidorelapolyrrhiza) .Environ. Pollut., 125, 385-392.

Zhang, W., Dong, L., Yan, H., Li, H., Jiang, Z., Kan, X., Yang, H., Li, A., \& Cheng, R. (2011). Removal of methylene blue from aqueous solutions by Straw based adsorbents in a fixed-bedcolumn. Chem. Eng. J. 173, 429-436. 